\title{
The persistence to slaughter age of scars resulting from damage inflicted to ostrich skins during the grow-out phase
}

\author{
A. Meyer ${ }^{1,3, \#, ~ S . W . P . ~ C l o e t e ~}{ }^{2}$, C.R. Brown ${ }^{4}$ and S.J. van Schalkwyk ${ }^{1}$ \\ ${ }^{1}$ Klein Karoo Agricultural Development Centre, P.O. Box 351, Oudtshoorn 6620, South Africa \\ ${ }^{2}$ Elsenburg Agricultural Development Institute, Private Bag X1, Elsenburg 7607, South Africa \\ ${ }^{3}$ School of Animal, Plant \& Environmental Sciences, University of the Witwatersrand, Private Bag 3, Wits 2050, South \\ Africa \\ ${ }^{4}$ Hartpury College (University of the West of England), Hartpury House, Hartpury, Gloucestershire, GL19 3BE, \\ England
}

\begin{abstract}
Damage to ostrich skins in the form of cuts and scratches obtained during the grow-out phase results in lower quality skins that fetch lower prices. This represents major financial losses to the ostrich industry. The stage at which such damage occurs and its persistence to slaughter age, when it affects skin grading, is not known. In this study we assessed the persistence through to slaughter age of wounds inflicted on the skins of ostrich chicks at ages 1, 4, 7, 10 and 13 months. Superficial and deep wounds were investigated by either scratching the skin with a nail, or by cutting through the skin with a scalpel blade. Experimental animals were slaughtered at either 11 or 14 months of age and visible scars were assessed on the processed skins. The length and surface area of each scar were measured to obtain an adjusted scar size. Orientation of lacerations (dorso-ventral or anterior-posterior) proved to be unimportant. Cut wounds were persistent to slaughter as were scratch marks, with only a small percentage of scratch wounds incurred at a young age not persisting to slaughter age. Mean scar size at slaughter became smaller with an increase in age at which the wounds were inflicted, except at 13 months of age where it was assumed that the wounds had not had sufficient time to heal properly. Deep cut wounds caused larger scars at slaughter age than superficial scratch damage. It seems that both superficial (scratches) and deep (cuts) wounds will result in lower skin grading, irrespective of age of infliction. This indicates that changes in chick rearing practices are necessary to reduce the incidence of skin damage if skin quality is to be improved.
\end{abstract}

Keywords: Ostrich leather, skin damage, lacerations

${ }^{\#}$ Corresponding author. E-mail: anelm@elsenburg.com

\section{Introduction}

Exotic leather is one of the main products of farmed ostriches and is worth an estimated R300 million per annum to the industry in South Africa (Van Zyl, 2001). Ostrich skins are graded according to size and quality, with poorer quality skins fetching lower prices. Leather quality is primarily defined by the absence of damage or defects to the hide or skin surfaces (Anon, 1999). With supply currently exceeding demand, quality control is stringent and the majority of ostrich skins presently produced receive low gradings due to visible skin defects. In a recent survey the average percentage of first grade skins from 94 producers of slaughter birds was only $39.7 \%$ (Nel et al., 2000). This results in substantial financial losses for the farmer.

The most common cause of low grading is skin damage of some description, mainly scratches and kick marks. These are presumably acquired during chick rearing under intensive conditions, but the specific causes and stage of acquiring skin damage are contentious. There is also uncertainty regarding the degree to which ostrich skins recover from injuries and the persistence of resultant scars to slaughter, when they affect grading. It is known that the process of wound healing is complex and dependent on a number of interacting factors (Gorin et al., 1996). Approximately 53\% of defects seen on wet salted ostrich skins are reputed to be healed wounds or scars, $37 \%$ partly healed sores and 10\% are fresh wounds (Walton, 2000). The origin or cause of these defects cannot easily be determined, making prevention of such injuries difficult. Scars are formed after a wound has healed, which would normally be after approximately four weeks (Walton, 2000). Once a scar has formed it is difficult to determine the age of the scar, and therefore the age of the chick at infliction. We reasoned that monitoring scar development following injuries would assist in determining what types of wounds cause the scars commonly recorded on processed skins, as well as giving an indication of the age at which wound infliction takes place. Knowledge of the stage of infliction as well as the type and persistence of damage will help to identify problem areas and aid in the development of management 
strategies that will minimize skin damage. We consequently investigated persistence through to slaughter age of wounds inflicted on ostrich skins at different ages in order to determine the importance of skin injuries during different grow-out phases as it relates to final skin grading.

\section{Materials and Methods}

Experimental birds used in the study were African Black ostriches (Struthio camelus domesticus) from the commercial flock maintained at the Klein Karoo Agricultural Development Centre at Oudtshoorn, South Africa. Management practices for rearing chicks and juveniles, as described by Bunter (2002), were implemented with minor changes as necessitated by the experimental design. The trial was carried out from September 2000 to October 2001.

Fifty chicks were selected from a group of one-month-old chicks reared by a breeding pair. Wounds were inflicted to the skins of each of these chicks under veterinary supervision. A small area on the back of the ostriches was plucked of feathers and cleaned with alcohol. The two main types of wounds, namely deep (full skin thickness) and superficial wounds (Snowden et al., 1997) were imitated. Full skin thickness incisions were created with a scalpel $(\mathrm{n}=44)$, whilst superficial scratches were created with a nail $(\mathrm{n}=6)$. Damage was inflicted in two directions: dorso-ventrally on the left flank of each animal and anteriorposteriorly on the right flank of each animal. Wounds were positioned next to the spine on the lower back, in the crown area (diamond-shaped area covered with feather follicles) of the skin. The exact location of each cut or scratch was marked with symbols tattooed on both sides of each wound with Indian ink to ensure visibility throughout the trial. A digital photograph was also taken of each wound. These images were used to locate specific lacerations that were not easily detectable at first glance. The procedure was repeated at 3month intervals at 4, 7, 10 and 13 months of age. Distinctive symbols were used for each repetition. Subsequent lacerations were made directly below or next to previous lacerations in order to facilitate comparison.

Of the 50 experimental birds, 10 (nine with cuts and one with scratches) died before slaughter of various causes unrelated to the experimental procedures. The remaining ostriches were slaughtered at $11(\mathrm{n}=$ $19)$ and 14 months $(n=21)$ of age. Apart from two skins that were lost during the tanning process, a total of 38 processed skins were assessed (34 with cuts and four with scratches) with a total of 346 individual lacerations (308 cuts and 38 scratches).

The length of each laceration was determined using a Digimatic Caliper. To obtain the surface area, each laceration was outlined with a $0.25 \mathrm{~mm}$ Rotring rapidograph pen and copied onto tracing film. The silhouettes were then enlarged to double the size, cut out, and passed through a LiCor LI3100 portable area meter for the determination of surface area. The resolution of the area meter was $1 \mathrm{~mm}^{2}$ and each silhouette was measured five times to obtain a mean surface area $\left(\mathrm{cm}^{2}\right)$.

Visibility of the two types of damage (cut or scratch) was compared using standard non-parametric $\mathrm{Chi}^{2}$ procedures or by Fisher's exact probability, depending on the numbers and frequencies of observations (Siegel, 1956). Further analysis was confined to skins where all lacerations were visible. Least square procedures were employed using the ASREML statistical package (Gilmour et al., 1999) to account for uneven subclasses. Initial mixed models included the random effects of the identity of the skin and the replicated measurements. Both these variances, however, went to the boundary of parameter space (zero). It was thus assumed that the measurements were sufficiently uncorrelated to allow analysis of variance and that the mean value based on the five replicates was extremely accurate. The surface area of each laceration was adjusted for length by analysis of covariance. A cubic spline was used to model the effect of age at infliction on the size of the lacerations (Verbyla et al., 1999). Both the linear and non-linear components of the spline were interacted with type of damage (cut or scratch) and orientation of the laceration (dorso-ventral or anterior-posterior). The covariate of laceration length was also interacted with age at infliction and type of damage.

\section{Results}

All 308 cut wounds left clearly visible scars that persisted until slaughter. Two scratch marks inflicted at one month of age on one of the ostrich skins were not visible at slaughter whereas all lacerations were visible on the other three skins with superficial scratch marks, suggesting that cuts (308 out of 308) and scratches $(36$ out of 38$)$ differed in visibility $\left(\mathrm{Chi}^{2}=8.433\right.$; d.f. $\left.=1 ; \mathrm{P}<0.01\right)$. It should, however, be noted that $94.7 \%$ of scratch marks still persisted to slaughter. 
For skins where all scars were visible when slaughtered at 14 months of age $(n=18$ for cuts and $n=3$ for scratches), interactions involving more than two factors were not significant $(\mathrm{P}>0.05)$, and were thus excluded from the discussion. The size of the scars at slaughter was independent of orientation of the laceration (3.48 $\pm 0.29 \mathrm{~cm}^{2}$ for dorso-ventral lacerations and $3.73 \pm 0.29 \mathrm{~cm}^{2}$ for anterior-posterior lacerations), but was dependent on type of damage, with cuts resulting in larger scars than scratches $(\mathrm{P}<0.05$; Figure 1$)$. Overall, mean laceration size amounted to $4.67 \pm 0.22 \mathrm{~cm}^{2}$ for cuts compared to $2.55 \pm 0.43 \mathrm{~cm}^{2}$ for scratches $(\mathrm{P}<0.05)$. When skins of ostriches slaughtered at 11 months were considered, corresponding means were $4.30 \pm 0.14 \mathrm{~cm}^{2}$ for cuts compared to $3.04 \pm 0.97 \mathrm{~cm}^{2}$ for scratches $(\mathrm{P}<0.05)$.

Although laceration scars persisted until slaughter in all cases, there was a general linear decrease at 14 months slaughter age in the size of scars from lacerations made on younger chicks compared to those made on older chicks (Figure 1). The smallest scars were for lacerations inflicted on chicks at 10 months of age, with those inflicted on 13 month old chicks showing a tendency to larger size by slaughter, presumably due to the short time available to heal, resulting in an apparent curvilinear response. A similar response was obtained for birds slaughtered at 11 months of age. Laceration size declined with age at infliction, with the smallest scars resulting from lacerations inflicted at seven months. No further decline was observed.

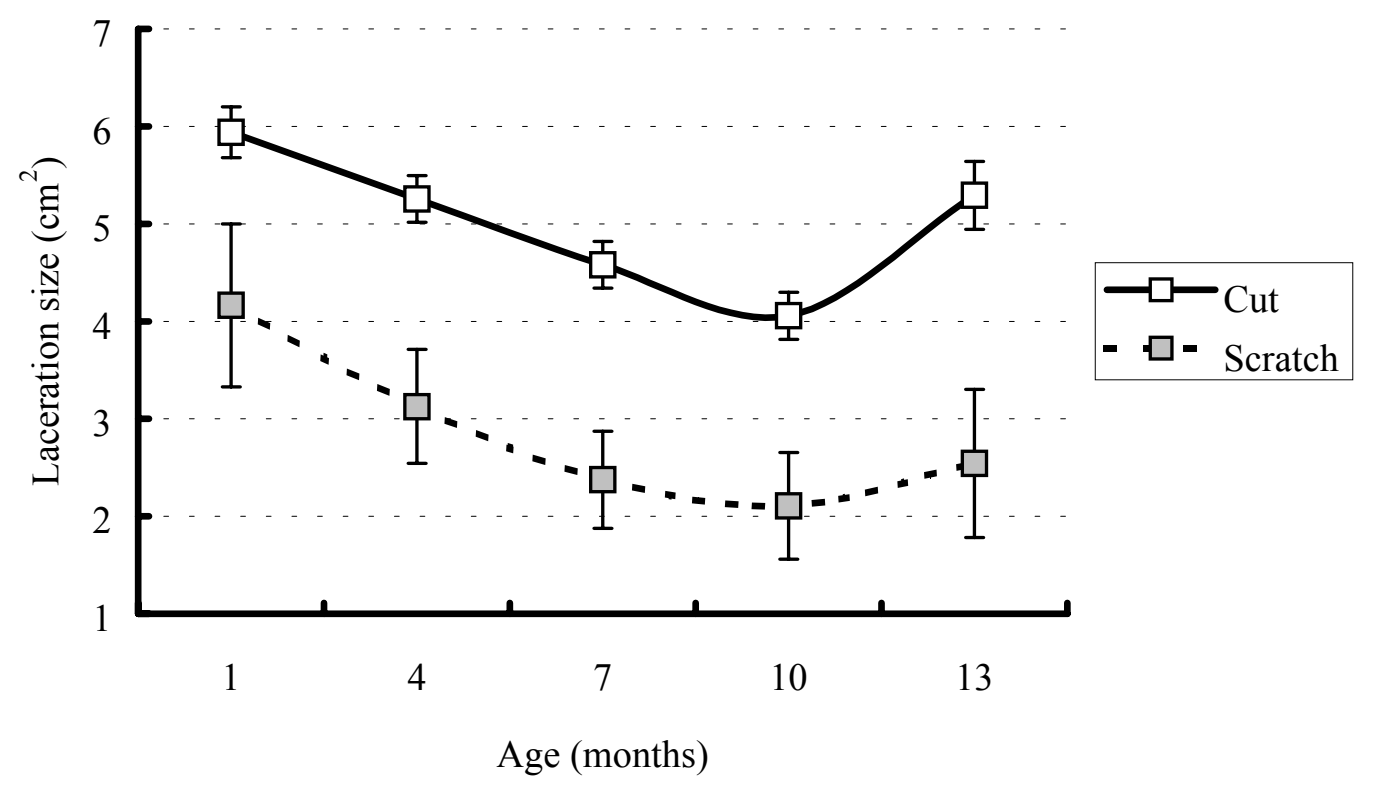

Figure 1 Mean ( \pm s.e.) laceration size as evaluated on the processed skin according age at infliction and type of damage for birds slaughtered at 14 months of age

During the analysis on birds slaughtered at 14 months of age, it was evident that laceration length interacted $(\mathrm{P}<0.05)$ with age at infliction and type of damage. The regression coefficient $( \pm$ s.e. $)$ of laceration area on laceration length amounted to $0.93 \pm 0.08 \mathrm{~cm}^{2}$ for cuts compared to $0.23 \pm 0.11 \mathrm{~cm}^{2}$ for scratches, for an increase of $1 \mathrm{~cm}$ in laceration length $(\mathrm{P}<0.05)$. Respective correlations were 0.67 and 0.36 . A scatter-plot depicting these relationships is presented in Figure 2. The generally larger size of cuts compared to scratches is also evident from Figure 2. When the interaction of laceration length with age at infliction was considered, it became clear that it resulted mainly from the difference between lacerations inflicted at 13 months of age, and those inflicted earlier (1-10 months). Due to the limited number of available skins with scratches, only skins with cuts were considered. Respective regression coefficients of laceration area on laceration length amounted to $1.54 \pm 0.25$ for cuts inflicted at 13 months compared to $0.84 \pm 0.09$ for cuts inflicted at earlier ages $(\mathrm{P}<0.05$; Figure 3$)$. The respective correlations were 0.73 and 0.67 . 


\section{Discussion}

Both superficial and deep incisional wounds were persistent to slaughter with clearly visible scar tissue developing, irrespective of the age of infliction. According to Snowden et al. (1997) both superficial and deep incisional wounds heal rapidly with minimal scarring, whilst exisional wounds are more likely to result in scarring. In this trial, however, both superficial and deep incisional wounds left readily visible scars, even though superficial damage in the form of minor scratches appeared to be more likely to heal without scarring.

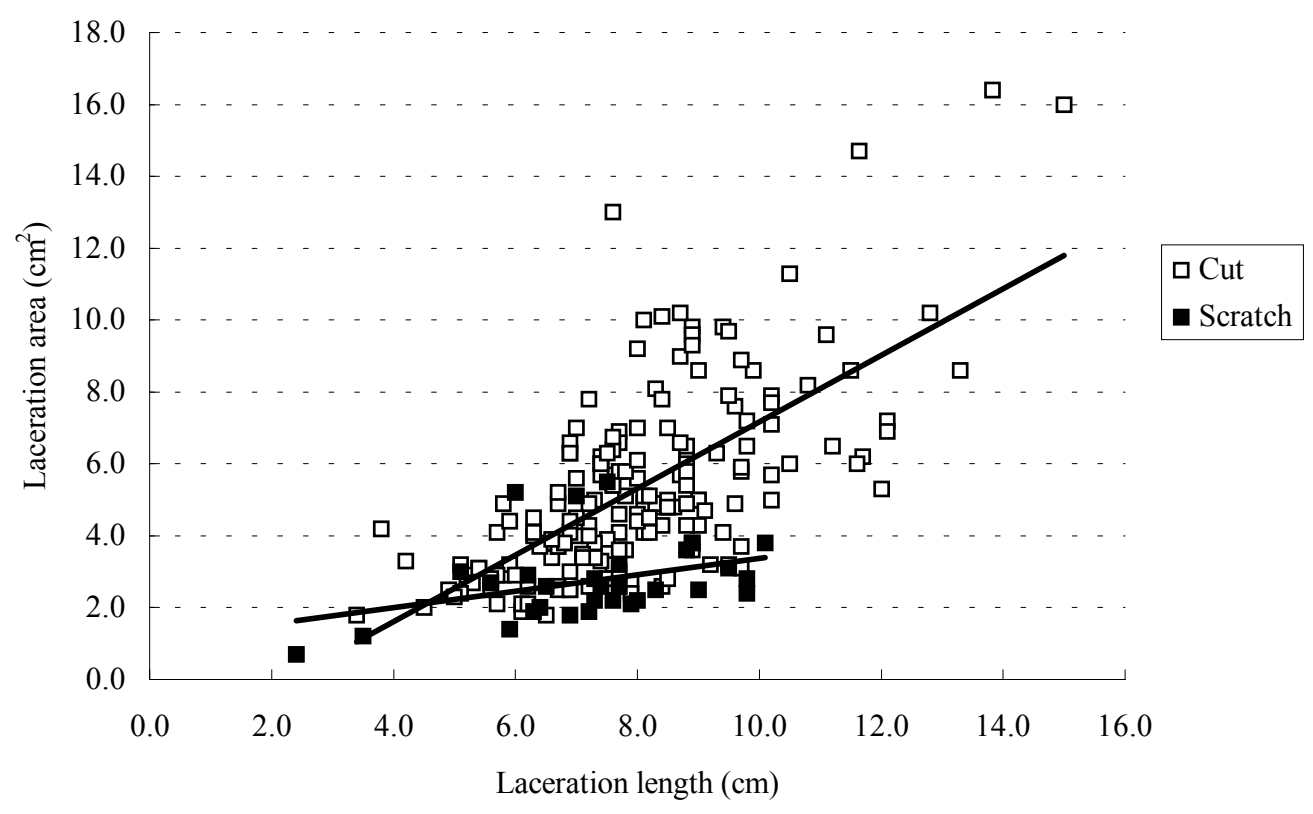

Figure 2 Scatter-plot depicting the relationship between laceration area and laceration length for cuts and scratches on birds slaughtered at 14 months of age

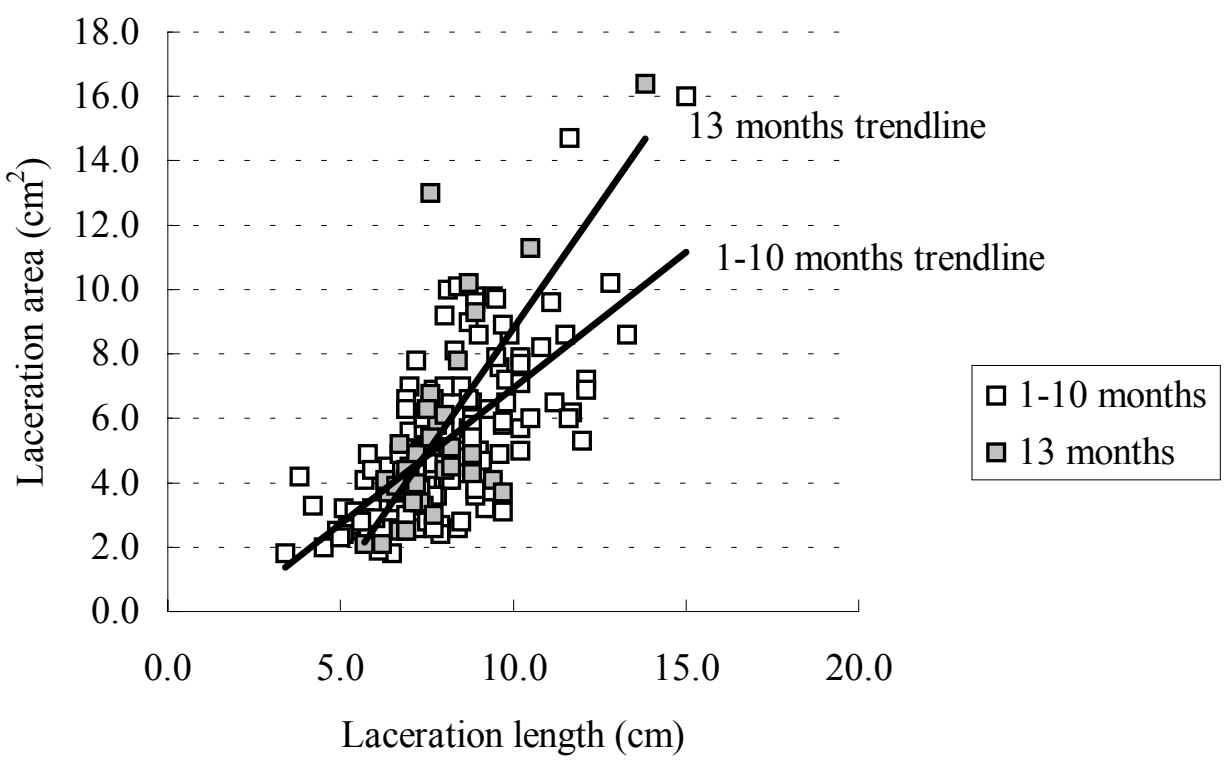

Figure 3 Scatter-plot depicting the relationship between laceration area and laceration length for cuts inflicted at one to 10 months of age and at 13 months of age respectively for birds slaughtered at 14 months of age 
Laceration size at slaughter age was independent of the orientation of infliction, but was dependent on the type of damage. The structure of ostrich skin, which comprises a collagen fibre matrix or weave structure (Russel \& Kohl, unpubl. report), probably explains why laceration size was independent of the orientation of infliction. Regarding type of damage, cuts resulted in significantly larger scars than scratches at slaughter ages of both 11 and 14 months. It is unclear how this result relates to the finding that laceration size is more closely related to laceration length in cut wounds than in scratch wounds. Furthermore, the laceration size of cuts inflicted at 13 months of age was more closely related to initial laceration length compared to cuts inflicted earlier. This may be related to the short interval between the infliction of the lacerations and slaughter (1 month). According to Walton (2000) the healing process may only be completed after approximately four weeks. Superficial wounds are likely to recover quicker, with less scar tissue forming. Deep wounds that damage the dermis and epidermis will naturally form more scar tissue, causing larger scars that are more pronounced at slaughter than those resulting from superficial wounds. Furthermore, the thin pliant skin of young chicks may prolong complete healing of deep wounds, like the cuts inflicted in the present study. From seven to 10 months of age the skin appeared to recover more easily from damage. In general, lacerations healed fairly rapidly, with most of the wounds completely healed within a month of infliction, with only scar tissue visible at slaughter. This suggests that the correct handling and transporting of ostriches in the month before slaughter are of extreme importance, since fresh and partly healed wounds are observed on an alarmingly high percentage of ostrich skins at slaughter (Walton, 2000). It should, however, be noted that the cut wounds in this study were clean surgical incisions which heal mostly by primary intention (Drew et al., 2001), whilst serious skin damage incurred during growth on ostrich farms will probably more often resemble exisional wounds, and will therefore heal by secondary intention. This process is more complicated, with delayed healing and the formation of more scar tissue (Drew et al., 2001). Superficial damage in the form of scratches has been identified as the main cause of ostrich skin damage (Meyer et al., 2002). Damage incurred during the early stages of a chick's life are thus as important, since scratches mostly result from the sharp claws of young chicks climbing on and over each other (Meyer et al., 2002).

Damage inflicted at a young age (one-month) generally resulted in larger scars at slaughter than damage inflicted at later ages, and particularly those inflicted at seven and 10 months of age. This suggests that scar development is closely linked with the overall growth of ostriches. A working hypothesis would be that scars grow in synchrony with the skin. Ostrich skin exhibits natural growth and development as the animal matures (Russel \& Kohl, unpubl. report). Scar tissue on the skin will thus also exhibit growth as the animal matures, with large scars resulting from wounds inflicted at a young age. It was, however, impossible to substantiate this contention from the literature. Ostrich skin may be unique with regard to its ability to heal, and with the formation and persistence of scar tissue.

These results emphasize the importance of skin damage obtained during the commercial rearing of ostrich chicks where one of the main targets is the production of high quality, defect-free leather. Nel \& Cloete (unpubl. data), found a tendency $(\mathrm{P} \approx 0.10)$ for producers that reared their own chicks to achieve better skin grading results than producers who bought in older chicks of three to six months of age for rearing to slaughter age. It is often alleged in the broader ostrich industry that producers specializing in chick rearing do not implement husbandry practices that limit skin damage. This allegation stems from the fact that their objective (to produce a viable chick at three to six months of age) differs from the slaughter producer's objective, which is the production of a good quality end-product (leather). The former tendency could be indicative of the importance of skin damage during the early stages of a chick's life, and supports the contention that damage incurred at these young ages is persistent to slaughter and should, therefore, be prevented. Preventative measures that should be considered, include proper infrastructure, better handling methods and optimal holding conditions.

\section{Conclusion}

Damage inflicted to ostrich skins during the animal's life cycle was persistent to slaughter, irrespective of age at infliction or type of damage (scratches or cuts). This is contrary to the common belief that damage contracted at a young age will disappear by slaughter age. Grading of ostrich skins is presently based on visible skin damage and it is clear that both types of damage will result in poor skin grading, with deep wounds causing larger, more visible scars. The results of this study emphasize the need to develop management practices for chick rearing that minimize the infliction of damage on ostrich skins. Producers 
should, therefore, apply good husbandry practices from the early stages of a chick's life in order to prevent skin damage that will be transferred to slaughter age, lowering the grading and value of ostrich skins, with consequent financial loss to the producer.

\section{Acknowledgements}

We thank the Klein Karoo Co-operative for financial assistance and co-operation during data collection at the abattoir and tannery. We also express our gratitude to the technical and other staff of the Klein Karoo Agricultural Development Centre for their support in the execution of the project. Finally, we gratefully acknowledge the role of the Animal Production Research Trust and Department of Agriculture of the Western Cape for making this project possible.

\section{References}

Anon., 1999. FAIR Project: Improving hide and skin quality. BLC Leather Technology Centre, Newsletter No. 2: Raw material problems and statistics, http://www.blcleathertech.com/fair/news2.htm.

Bunter, K.L., 2002. The genetic analysis of reproduction and production traits recorded for farmed ostriches (Struthio camelus). Ph.D. dissertation, University of New England, Australia.

Drew, A.F., Liu, H., Davidson, J.M., Daugherty, C.C. \& Degen, J.L., 2001. Wound-healing defects in mice lacking fibrinogen. Blood 97, 3691-3698.

Gilmour, A.R., Cullis, B.R., Welham, S.J. \& Thompson, R., 1999. ASREML - Reference manual. NSW Agriculture Biometric Bulletin No. 3. NSW Agriculture, Orange Agric. Inst., Forest Road, Orange 2800, NSW, Australia.

Gorin, D.R., Cordts, P.R., LaMorte, W.W. \& Menzoian, J.O., 1996. The influence of wound geometry on the measurement of wound healing rates in clinical trials. J. Vasc. Surg. 23, 524-528.

Meyer, A., Cloete, S.W.P., Brown, C.R. \& van Schalkwyk, S.J., 2002. Declawing ostrich (Struthio camelus domesticus) chicks to minimize skin damage during rearing. S. Afr. J. Anim. Sci. 32, 192-200.

Nel, C.J., Cloete, S.W.P., Lambrechts, H. \& Clark, J., 2000. Bestuurspraktyke wat die gradering van volstruisvelle kan beïnvloed. Elsenburg J. 2000, 52-58.

Siegel, S., 1956. Non parametric statistics for the behavioural sciences. McGraw-Hill Book Company Inc., New York, USA.

Snowden, J.M., Roberts, M. \& Cross, S., 1997. Determining the efficacy of emu oil in wound healing and cellular regeneration. RIRDC Research Paper No. 97, p. 2.

Van Zyl, P.L., 2001. 'n Ekonomiese evaluering van volstruisboerdery in die Oudtshoorn-omgewing. MSc (Agric)-tesis, Universiteit van Stellenbosch, South Africa.

Verbyla, A.P., Cullis, B.R., Kenward, M.G. \& Welham, S.J., 1999. The analysis of designed experiments and longitudinal data using smoothing spines. J. Royal Stat. Soc. Series C 48, 249-311.

Walton, E., 2000. Can some Ostrich skin defects be avoided? East Cape Ostrich Producers Newsletter No. 2. 